\title{
(6)
}

Ana María Arrieta Casas*

Lucía Frechilla Flórez*

Antonio Galilea Jiménez*

Mercedes Núñez Román**

Mar Sanmamed Aramburu***

Rosa Tortajada Perrote*

\section{HISTORIA DE CITES EN ESPAÑA: 35 AÑOS DE CONTROL DEL COMERCIO INTERNACIONAL DE ESPECIES AMENAZADAS}

Durante los años sesenta, debido al excesivo uso comercial de los recursos naturales, muchos Gobiernos, y también la sociedad, empiezan a tomar conciencia de la necesidad de adoptar medidas que permitan equilibrar el uso sostenible de los recursos naturales y la conservación de los mismos. Ello llevó a que veintiún países firmaran en el año 1973 el Convenio sobre el Comercio Internacional de Especies Amenazadas de Fauna y Flora Silvestres (CITES). Este convenio ha conseguido convertirse en un exitoso instrumento comercial al servicio de la conservación y el uso sostenible de las especies, capaz de combinar de manera eficaz la relación entre comercio y medioambiente. A día de hoy cuenta con la amplia participación de 184 países, habiendo sido España el $89 .^{\circ}$ en adherirse a él en el año 1986. Desde entonces, la Secretaría de Estado de Comercio ha estado al frente de la aplicación de este convenio como autoridad administrativa principal del mismo realizando una encomiable labor ampliamente reconocida a nivel internacional.

Palabras clave: especies amenazadas, flora, fauna, Autoridad Administrativa de España, comercio, SOIVRE.

Clasificación JEL: F18, F13, Q56, Q57, Q58.

\section{Introducción}

Tras la firma del Convenio sobre el Comercio Internacional de Especies Amenazadas de

* Jefa/e de Servicio CITES.

** Coordinadora Nacional CITES.

*** Técnico Superior CITES.

Versión de noviembre de 2021.

DOI: https://doi.org/10.32796/bice.2021.3141.7307
Fauna y Flora Silvestres (CITES) en 1973, y su aplicación inicial en 1975, en España se estableció un grupo de trabajo en la Subdirección General de Inspección, Certificación y Normalización del Comercio Exterior, con dos objetivos fundamentales, en primer lugar, el de preparar la adhesión de España al citado convenio y, en segundo lugar, conseguir la protección de importantes sectores nacionales, directamente $D$ 
Ana María Arrieta, Lucía Frechilla, Antonio Galilea, Mercedes Núñez, Mar Sanmamed y Rosa Tortajada

afectados por el mismo, como eran el de la exportación de zapatos o el de la curtición de pieles, ambos radicados en la Comunitat Valenciana.

Como consecuencia de su trabajo, sobre la base del artículo 10 del convenio, que permite el comercio con países no firmantes del mismo, inicialmente se estableció un modelo de certificado provisional que garantizara el cumplimiento de las condiciones instituidas en él por las exportaciones españolas, que inmediatamente fue reconocido por el resto de las partes firmantes del convenio. En segundo lugar, diseñó y estableció la infraestructura necesaria y, a través de los Centros de Inspección de Comercio Exterior del entonces Ministerio de Economía y Hacienda, desde 1977 se comenzó a emitir permisos y certificados asimilados a los permisos y certificados CITES. Igualmente, desde ese año, se ejercían funciones de control de especímenes, sus partes y sus manufacturas que eran reexportados, principalmente de los sectores del calzado y marroquinería. Esto permitió que el comercio exterior de esos productos no se viera afectado en los países de destino que sí eran signatarios del convenio.

Con el fin de asegurar la continuidad de la colaboración de los Centros de Inspección de Comercio Exterior con la aplicación del convenio, se consideró necesario promulgar un Real Decreto para asegurar el control de los productos afectados por CITES con extensión de sus competencias a todas las operaciones de comercio exterior. Así, tras la deliberación del Consejo de Ministros en su reunión del día 22 de mayo de 1985, se acordó el nombramiento de las autoridades administrativa y científica de acuerdo a lo establecido en el artículo IX del convenio.

La infraestructura creada posteriormente se desarrolló en el ámbito de la Secretaría General de Comercio, y permitió la adhesión de España al Convenio CITES en mayo de 1986 (Instrumento de Adhesión de España de 16 de mayo de 1986 al Convenio sobre el Comercio Internacional de Especies Amenazadas de Fauna y Flora Silvestres [CITES], publicado en el BOE n. 181 de $30 / 07 / 1986)$. La entrada en vigor de dicha adhesión fue el 28 de agosto de 1986, constituyendo el país número 89 de las Partes de CITES.

Con la entrada en vigor del convenio, tuvo de ponerse en marcha un sistema complejo administrativo: organizar el reparto de competencias entre autoridades administrativa y científica, desarrollar normativa de regulación y control comercial, así como legislación sancionadora entre otras muchas funciones.

\section{El control del comercio de especies CITES en España a través de la red de Direcciones Territoriales y Provinciales de Comercio}

\subsection{Funciones de la Autoridad Administrativa CITES de España}

Las funciones de la Autoridad Administrativa CITES de España se ejercen con el apoyo de la red territorial existente a través de las Direcciones Territoriales y Provinciales de Comercio (DT/DP). La estructura de esta autoridad está establecida en dos bloques interconectados y dependientes entre ellos, que son los Servicios Centrales ubicados en Madrid, dentro de la Subdirección General de Inspección, Certificación y Asistencia Técnica del Comercio Exterior, y una red periférica compuesta por 31 DT/DP distribuidas por las aduanas y puestos claves de la geografía española, con la denominación de Servicio Oficial de Inspección, Vigilancia y Regulación de las Exportaciones (SOIVRE). 
Las funciones correspondientes a la aplicación del Convenio CITES se llevan a cabo en dichas DT/DP por personal perteneciente a los cuerpos de Inspectores e Ingenieros Técnicos del SOIVRE, que desarrollan sus funciones, en cumplimiento de su competencia para la ejecución de la política comercial española y de internacionalización exterior, de forma profesional, rigurosa y brillante con el objetivo principal de cumplir escrupulosamente los objetivos del Convenio CITES combinando el control comercial con la sostenibilidad y conservación, y colaborando muy activamente en la prevención y erradicación del comercio ilegal de vida silvestre.

Los Servicios Centrales ubicados en Madrid son los encargados de coordinar la aplicación de dicho convenio en todo el territorio español $y$, para ello, cuentan con distintas herramientas de trabajo.

Las DT/DP emiten, si procede, los permisos y certificados necesarios para aquellos especímenes amparados por la legislación internacional y comunitaria CITES.

Bien sea para la expedición de documentos CITES de importación, exportación o reexportación, así como certificados comunitarios (válidos únicamente dentro del territorio de la Unión Europea), el procedimiento general que se sigue en cada una de estas DT/DP es el siguiente:

- Iniciación a petición del administrado que realiza una solicitud de permiso o certificado CITES, en la DT/DP de su demarcación territorial correspondiente, aportando toda la documentación pertinente.

- Estudio minucioso de todo ello.

- Si se considera necesario, se solicita información adicional, y, en ocasiones, es preciso contactar con las autoridades administrativas de otros países parte del Convenio CITES con el fin de verificar la información y/o documentación aportada. Esta actividad se lleva a cabo en los Servicios Centrales.

- Finalizado el estudio de la documentación de la solicitud, se procede a emitir el permiso o certificado CITES o a su denegación justificando la misma.

En las operaciones de comercio exterior, previo al despacho aduanero, los inspectores de las DT/DP de aquellos puntos fronterizos designados realizan la inspección de las mercancías con el objeto de comprobar que esta coincide con lo que se ha autorizado. Esta función no está en sí asignada a las autoridades administrativas CITES, sino que corresponde a las aduanas llevarla a cabo. Sin embargo, en España, al contar con inspectores especializados en los puntos fronterizos en el momento de la firma del Convenio CITES, consideró una ayuda importante para las aduanas que se realizara por ellos.

En el caso de los certificados CITES (comunitarios), dichas inspecciones se realizan antes de emitir el documento, y de esta forma se verifica que toda la documentación e información que se ha aportado es correcta. Según los últimos datos, en el año 2020 se emitieron un total de 11.368 certificados CITES.

\subsection{Regularizaciones}

Una parte importante del trabajo realizado en las DT/DP corresponde a lo que se conoce como «regularizaciones» o «legalizaciones». El objetivo de estos procedimientos es regularizar la situación legal de los especímenes de especies CITES por diversas circunstancias, siendo la $\triangleright$ 
Ana María Arrieta, Lucía Frechilla, Antonio Galilea, Mercedes Núñez, Mar Sanmamed y Rosa Tortajada

principal el reconocimiento de los mismos como especímenes preconvención.

Las regularizaciones se realizan por muy diversas circunstancias. A modo de ejemplo y por ser la más habitual, se puede indicar la situación de los particulares que durante muchos años tienen un espécimen de una especie incluida en los apéndices del Convenio CITES o en los anexos del Reglamento de la Unión Europea sin ser conscientes de que precisaban un documento CITES para demostrar el origen legal y, si así lo desearan, para poder venderlo. Esta situación es muy habitual en personas en posesión de pequeñas piezas de marfil que en su momento adquirieron legalmente en España cuando aún no se precisaban permisos para su entrada y comercialización en la Unión Europea.

Es preciso indicar aquí que España ha sido un país con gran tradición en importación y venta de marfil y, como otros países europeos, ha tenido colonias en África (Guinea Ecuatorial). Muchos españoles emigraron a ellas por motivos de trabajo, trayéndose a su regreso a España, en mayor o menor cantidad, tanto marfil en bruto como figuras talladas que trasladaban en grandes baúles o cajones de madera. Algunos relataban incluso que tuvieron que salir con gran premura de dicho país cuando la colonia se independizó.

Además del marfil importado directamente de África, hasta 1990, año en el que la Unión Europea prohibió la importación de marfil con finalidad comercial consecuencia de la inclusión del elefante africano (Loxodonta africana) en el apéndice I del convenio, en España y en Europa se importaron legalmente aproximadamente millón y medio de figuras de marfil talladas procedentes de países asiáticos. Se estima que solo en España entre 1986 y 1990 se importaron más de 40.000 figuras de marfil, además de gran cantidad de marfil en bruto1. La mayoría de las personas que adquirieron figuras de forma legal en aquellos años no conservan facturas de compra y deben recurrir a un procedimiento de regularización para acreditar el origen legal.

Fruto de todas esas importaciones realizadas en la más absoluta legalidad, estos miles de figuras están en manos de particulares que en ningún caso constituyen un entramado de comercio ilegal, sino que desconocen que aquello que adquirieron de forma lícita no puede venderse directamente en la actualidad, pues precisa de su regularización previa.

Otros especímenes motivo de regularización son los trofeos de caza. Actividad de gran tradición y muy arraigada en España que ha supuesto la creación, en algunos casos, de grandes pabellones en los que guardar y exponer los trofeos.

Las solicitudes de regularización suelen estar motivadas por el fallecimiento de los titulares de los trofeos, que dejan a sus herederos en una situación administrativa en la que precisan de documentación que acredite su origen legal.

Estas regularizaciones también han tenido como protagonistas abrigos de piel de distintas especies de felinos que muchas personas adquirieron desde hace varias décadas o, igual que los trofeos de caza, los heredaron de familiares. Al estar elaborados estos abrigos con pieles de especies que se encuentran con el mayor nivel de protección, se precisa de un certificado CITES.

Lo mismo ocurre con mascotas de especies que se adquirieron antes de que estas estuvieran protegidas y que ahora precisan $D$

Estimación con datos procedentes de la Base de Datos sobre el Comercio CITES (versión 2021.1), disponible en la página web oficial de la Secretaría CITES (https://trade.cites.org/). 
también del documento emitido por la autoridad administrativa.

Para llevar a cabo las regularizaciones se admite la aportación de cualquier prueba admitida en derecho, como pueden ser: facturas, fotos antiguas -en las que fuera posible reconocer el objeto a legalizar, así como estimar una fecha-, documentos de embarque, pólizas de seguros y cualquier documento o prueba que permita demostrar que se está en poder de todos esos especímenes desde, al menos, la fecha de la firma de España del Convenio CITES (año 1986).

La tarea de investigación y evaluación de la documentación y pruebas aportadas siempre ha resultado interesante. Esto es debido a que las historias relatadas por los solicitantes conforman el expediente a evaluar. Ejemplos del contenido de estos expedientes son las cartas antiguas escritas a mano, fotos de cacerías con los guardas, sherpas o la familia, retratos de los hijos de los interesados que nacieron en aquellas colonias, otras fotografías de familia con mobiliario al fondo abarrotado de figuras de marfil, así como fragmentos de películas antiguas y un largo etcétera de documentación y demás pruebas que permiten concluir un expediente, regularizando o denegando lo solicitado.

Durante los años que se ha estado ejerciendo esta tarea la casuística encontrada ha sido muy diversa, y es justo reconocer que la mayoría ha sido información fidedigna que permitía avalar la regularización. En el lado contrario, y a modo de anécdotas, se puede mencionar haber identificado fotografías falsificadas, licencias de caza manipuladas, facturas en las que se indicaba un número de teléfono móvil emitidas en un año en el que todavía no existían esos teléfonos, algunas de ellas emitidas en euros, siendo anteriores a la entrada en vigor de dicha moneda, o utilizar una fotografía supuestamente de 1940 pero que resultó ser del nieto (por el parecido físico con su padre), ya que en la imagen aparecía el niño con una máquina de juegos (Game Boy) que no llegó a Europa hasta 1990.

En todo este proceso se lleva a cabo una inspección de los objetos que se pretenden regularizar. De dichas inspecciones, sobre todo en el caso de ejemplares vivos, son varias las anécdotas y dificultades que a lo largo de los años se han compartido, e incluso algunas de ellas pusieron en riesgo la vida de los inspectores. Algunos de estos han sufrido accidentes durante las inspecciones, siendo, sin duda, la peor la de un inspector que fue mordido por un chimpancé lo que le provocó una septicemia que afortunadamente pudo superar. El recuerdo de aquella tortuosa inspección fue la pérdida de la falange de un dedo como consecuencia del mordisco.

\subsection{Control de criadores y viveristas}

El control y certificación de la cría en cautividad en el caso de animales y de la reproducción artificial en el caso de plantas es otra de las funciones de la Autoridad Administrativa CITES desempeñada por el personal de las DT/DP. Con ella se controla y certifica que los especímenes que se utilizarán para criar o reproducir son de origen legal y que las crías o plantas producidas pueden tener fin comercial.

El control que llevan a cabo las DT/DP consiste en la evaluación de documentación acreditativa de los stocks parentales, la inspección física de las instalaciones con el fin de comprobar la correspondencia de los especímenes con la documentación aportada y la consecuente certificación de las crías o plantas reproducidas artificialmente. 
Ana María Arrieta, Lucía Frechilla, Antonio Galilea, Mercedes Núñez, Mar Sanmamed y Rosa Tortajada

También cabe destacar la tramitación del registro ante la Secretaría CITES de criadores de especímenes de especies del apéndice I con fines comerciales. Este complicado proceso de registro ha sido superado por cinco criadores españoles de las siguientes especies: Falco peregrinus, Falco cherrug y Falco rusticolus.

De los aproximadamente 3.200 criadores y 70 viveristas controlados por las DT/DP, el grueso lo ocupan las aves rapaces. Las rapaces criadas en cautividad en España tienen una gran demanda en determinados países por su calidad para el uso en cetrería, resultando ser una actividad económica muy importante.

Tanto en el caso de las regularizaciones de especímenes de especies del anexo A como en los especímenes criados en cautividad igualmente de especies del anexo A, para acreditar su origen legal es preciso emitir un certificado CITES conocido como certificado de uso comunitario. En estos casos, se realiza una inspección física previa a la emisión de los documentos.

Existen en la memoria de los inspectores numerosas anécdotas y momentos entrañables para el recuerdo vividos con los criadores. Entre ellos pueden mencionarse momentos en que los inspectores, en sus visitas a los criadores de rapaces, cuyos centros de cría se encuentran en lugares remotos de montaña, quedaban atrapados con su vehículo en un barrizal y tenían que ser «rescatados» por estos criadores, a los que agradecían enormemente su predisposición a ayudar y su destreza en el entorno natural.

\subsection{Otras funciones del control de comercio CITES realizadas por las DT/DP}

España es uno de los principales países importadores de pieles exóticas de reptiles (distintas especies de Python, Varanus, Crocodylus, etc.) empleadas en la elaboración de productos de marroquinería (zapatos, bolsos, correas de reloj, carteras y un largo etcétera) para su posterior reexportación, e incluso simplemente para la preparación, curtido y coloración de pieles antes de su salida a otros países.

Este control es arduo, ya que se trata de pieles que deben venir con un número de precinto que debe ser comprobado. Se hace preciso llevar un control de los saldos de pieles para evitar que se exporten más de las que se importan. Asimismo, en el caso de reexportación es necesario controlar que las pieles que han sido simplemente curtidas o tratadas mínimamente también estén precintadas y comprobar que coinciden con las que fueron importadas. Esto es posible gracias a que siempre se conserva la trazabilidad de las mismas mediante los documentos y las fotografías que las acompañan.

En este sentido, se colabora con importantes empresas del mundo de la marroquinería, ya que las marcas internacionales necesitan tener a tiempo los documentos de aquellos artículos elaborados con pieles exóticas, los cuales serán adquiridos en sus puntos de venta por particulares (normalmente turistas cuya estancia en España es breve) que acuden a comprar, generalmente, pequeños y grandes artículos de piel como bolsos y carteras. En el momento de la compra, el establecimiento les entrega el correspondiente certificado CITES de reexportación. Su compromiso de claridad y colaboración con la autoridad administrativa ha sido siempre palpable y se les ha ayudado a solventar a tiempo las posibles trabas que hayan podido surgir por la pérdida o extravío de los mismos, lo cual ha ocurrido únicamente en contadas ocasiones. 
Otro punto importante para finalizar aquellas labores llevadas a cabo en las DT/DP, en colaboración con los Servicios Centrales, es el de conseguir que empresas reexportadoras o envasadoras de caviar consigan su registro frente a Secretaría CITES. Este registro aparece publicado en la página web de CITES (https://cites.org/eng) y permite comprobar en cualquier momento, por parte de cualquier país receptor de caviar, que tanto la mercancía como la documentación que la acompaña han sido controladas en todo momento por la Autoridad Administrativa CITES de España y que la empresa que consta como titular del documento cumple con los requisitos necesarios para la manipulación y comercio de esa mercancía tan preciada en muchos países.

Se comprueban las instalaciones donde se va a manipular la mercancía, se supervisa la legalidad del stock con el que la empresa cuenta y se lleva un control del mismo en todo momento. Se inspeccionan las latas, el cierre de estas, su etiquetado y, si todo es correcto, se propone su registro ante la Secretaría CITES.

En 2021 están registradas un total de dieciséis empresas del sector del caviar y la carne de esturión que cuentan con todos los avales de calidad y cumplimiento de la legalidad CITES necesarios en este importante sector.

\subsection{Apoyo a otras autoridades}

Desde el inicio de la aplicación de CITES en España, una labor importante ha sido la de dar apoyo a otras autoridades. Entre ellas cabe destacar la colaboración en la identificación de aquellos ejemplares que son objeto de intervención o decomiso y que forman parte de un expediente administrativo o judicial. El apoyo consiste en la elaboración de informes que incluyen la determinación de la especie, su grado de protección, la documentación necesaria para acreditar el origen legal y una valoración económica de los mismos, ya que el procedimiento sancionador así lo exige.

Otro apoyo importante de esta autoridad administrativa es el de asistir a otras autoridades encargadas de velar por el cumplimiento de la normativa CITES, entre las que destaca el Servicio de Protección de la Naturaleza de la Guardia Civil (SEPRONA), con el que la colaboración, tanto por parte de los Servicios Centrales como de las DT/DP, ha sido muy estrecha y directa, pudiendo afirmar que el número de veces que se ha contribuido elaborando informes y ayudando de diversas maneras ha sido superior a diez mil. Otras autoridades con las que igualmente se colabora son el Servicio de Vigilancia Aduanera, Policía local, Policía Nacional, aduanas, juzgados y otras autoridades locales y autonómicas.

Asimismo, se está en contacto con todas las autoridades administrativas y de observancia de cualquiera de los países firmantes del Convenio CITES, se les presta apoyo en su labor y se les facilita toda aquella información que solicitan. De esa estrecha colaboración ha surgido, en varias ocasiones a nivel europeo, la identificación de personas cuya actividad quedaba lejos del cumplimiento del convenio: los traficantes ilegales.

Qué mejor reconocimiento a esta labor de colaboración que el otorgamiento, por parte de la Guardia Civil, de la cruz al mérito a cinco personas de la autoridad administrativa, así como diplomas de agradecimiento a varios inspectores y otras menciones y condecoraciones de otros organismos policiales.

Todas las labores enumeradas son fundamentales para el control del comercio legal que la aplicación del Convenio CITES permite y para lo cual ha sido gestado. Para su $\triangleright$ 
Ana María Arrieta, Lucía Frechilla, Antonio Galilea, Mercedes Núñez, Mar Sanmamed y Rosa Tortajada

correcta realización es fundamental que todas aquellas personas que lo llevan a cabo estén suficientemente preparadas para ello y que su formación sea continua. Así pues, la preparación de este personal y su selección ha sido de gran importancia desde el principio. Gracias a ello, la tarea que supone la aplicación del Convenio CITES en España, desde sus inicios en 1986, ha sido desempeñada con gran éxito, y esto ha supuesto a nuestro país un amplio reconocimiento internacional que pone en valor el trabajo realizado en todos estos años.

\section{El comercio ilegal de especies CITES}

Desde que España firmó la adhesión al Convenio CITES en 1986, que surte efectos desde el 28 de agosto de ese mismo año, la Autoridad Administrativa CITES ha participado activamente en todas las operaciones contra el tráfico ilegal de especies listadas, conjuntamente con las aduanas - autoridad administrativa adicionaly los diferentes cuerpos de seguridad del Estado, principalmente el SEPRONA, de la Guardia Civil, así como con las unidades medioambientales de la Policía local, autonómica y Nacional. Asimismo, ha colaborado regularmente con todos los países parte de CITES mediante el intercambio de información sobre tráfico ilícito de especies animales o vegetales en el que participaran personas $\mathrm{u}$ organizaciones criminales vinculadas de algún modo al territorio español.

\subsection{Operaciones destacadas por grupos taxonómicos}

Las exitosas operaciones llevadas a cabo han ido en aumento gracias a la colaboración entre Administraciones, en la que merece destacar la creciente implicación del Ministerio Fiscal, a través de la Fiscalía Coordinadora de Medio Ambiente y Urbanismo, y el apoyo técnico y pericial que la Autoridad Administrativa CITES ha prestado en todo momento a los citados cuerpos policiales, colaboración acrisolada por una ya larga experiencia.

\subsubsection{Aves}

Con la colaboración internacional de los países de origen, en una operación iniciada en el año 2016 y que finalizó en 2018, se consiguió desmantelar dos grupos organizados que traficaban con aves vivas, protegidas en CITES, y de otras especies, transportadas sin los más básicos requisitos de bienestar animal —como las normas IATA de transporte aéreo-y, en consecuencia, con un índice de mortalidad de más del $50 \%$, en vuelos procedentes de África y de América.

Asimismo, se intervinieron en frontera huevos en fase de incubación transportados con la intención de ser blanqueados como de aves criadas en cautividad (loros, guacamayos y tucanes), siendo necesaria la ampliación de la operación a los criaderos de destino, que culminó con la posterior condena por vía penal y/o sanción administrativa. Estas intervenciones se realizaron en tres operaciones distintas en los años 2005, 2014 y 2016, respectivamente.

En el año 2013, en un caso de contrabando sin precedentes, se logró la condena de un grupo que traía de Sudamérica maletas cargadas con pieles de aves y mamíferos para taxidermizar, protegidos o no, con destino a colecciones privadas. Los especímenes decomisados, más de cuatrocientos, engrosaron el patrimonio científico del CSIC, añadiendo especies de las que carecían, favoreciendo así la investigación. 
Por su alto valor biológico, algunas aves vivas intervenidas en dichas operaciones se destinaron a programas de conservación ex situ de la especie en zoológicos europeos, asegurando el valor genético de los ejemplares.

\subsubsection{Maderas}

En los años 2003 y 2004 se llevaron a cabo distintas operaciones relativas al tráfico ilícito de maderas protegidas (Dalbergia spp., Swietenia spp., Guaiacum spp., etc.), en sus diversas formas de presentación - troncos, tablones, laminados, productos terminados como instrumentos musicales (guitarra clásica)—, lo que contribuyó a lograr un riguroso control de las existencias en las empresas nacionales y a promover el prestigio internacional de estas y su comercio legal y sostenible.

\subsubsection{Anguila europea}

Cuando se iniciaba la temporada, desde 2009 a 2020, a fin de impedir el tráfico ilegal de esta especie, se realizaron múltiples operaciones que conllevaron una especial dedicación, dado que se trataba de especímenes vivos que había que reubicar con rapidez, y las incautaciones se realizaban en todo momento (fines de semana, madrugada, etc.).

De igual forma, desde que se prohibiera el comercio exterior en la UE con esta especie, en cada temporada de pesca se ha participado con el SEPRONA y Europol en todas las operaciones desarrolladas. Tal es así que los representantes del Gobierno de la República Popular China -mayor productor mundial de anguilas procedentes de piscifactoría-, en la reunión del Comité Permanente de CITES del año 2018, mostraron un gran interés en negociar con España un acuerdo comercial sobre esta especie, que asegurara un cupo de abastecimiento por temporada.

La reintroducción de las angulas intervenidas se consiguió mediante la coordinación con el SEPRONA, las CC. AA. y el centro de investigación pesquera AZTI (Instituto de Ciencia y Tecnología Marina y Alimentaria), que jugó un papel decisivo. Asimismo se consiguió elevar la gravedad de los hechos al ámbito internacional: Consejo y Comisión de la UE, países parte de CITES - a través de su Secretaría-, UNODOC (United Nations Office on Drugs and Crime), Interpol (Organización Internacional de Policía Criminal), OMA (Organización Mundial de Aduanas), etc., lo que se tradujo en la creación de grupos de trabajo y propuestas aceptadas con repercusión en el comercio exterior de la UE.

\subsubsection{Reptiles}

Este grupo de animales ha sido uno de los olvidados en el comercio ilícito a nivel mundial. A raíz de una operación conjunta de SOIVRE, Fiscalía Coordinadora y SEPRONA que tuvo lugar en el año 2017, se pusieron de manifiesto el conjunto de especies traficadas, el modus operan$d i$, los lugares y las formas de blanqueo, así como las redes de tráfico internacionales, lo cual contribuyó a desarrollar la lucha contra su tráfico en el ámbito europeo, con la implicación de Europol y la creación de un grupo de trabajo específico en el seno de la Comisión Europea, con medidas de control que permitieron intervenir especímenes valiosos en todos los sentidos.

\subsubsection{Marfil}

La implicación del SOIVRE se inició a raíz de la participación, en 1998, en los cursos de identificación, a cargo del director del Laboratorio Forense de EE. UU., llevados a cabo $D$ 
Ana María Arrieta, Lucía Frechilla, Antonio Galilea, Mercedes Núñez, Mar Sanmamed y Rosa Tortajada

en el Máster CITES organizado por la Universidad Internacional de Andalucía en su sede de Baeza.

Los conocimientos adquiridos se fueron ampliando con la experiencia a través del control de existencias de los últimos artesanos en activo en España, el comercio legal de marfil, la colaboración con las federaciones de anticuarios, el comercio exterior, las colecciones de los museos de arte nacionales o privados, las visitas a las salas de subastas y las intervenciones en estrecha colaboración con el SEPRONA, así como a través de los numerosos cursos de formación impartidos a responsables CITES de otros países, Guardia Civil, funcionarios, etc.

En consecuencia, se dispone de un personal inspector con conocimientos suficientes para peritar las piezas en cuanto a la especie de la que provienen, la época de talla, el valor de mercado y la antigüedad, así como otros aspectos, favoreciendo de este modo el comercio legal y la exhibición de obras de arte fruto de nuestro rico patrimonio cultural.

\subsubsection{Trofeos de caza}

A pesar de ser España un país con una larga tradición cinegética, que cuenta con colecciones privadas destacadas que cumplen con la normativa de aplicación, no siempre es legal la comercialización de trofeos cinegéticos.

En consecuencia, tanto en frontera como en interior, se ha participado en múltiples operaciones en virtud de las cuales se ha incautado gran variedad de especies protegidas para ser naturalizadas como trofeos de caza.

Los especímenes no regularizados, o sin documentación acreditativa de su legal procedencia, han sido decomisados implicando sanciones por vía administrativa y/o penal, que han servido para detener y prevenir este tipo de oferta $y$ demanda, y han permitido nutrir a museos, científicos y profesores de material útil para la investigación y la formación técnica de multitud de funcionarios de muy diversos países.

\subsection{Participación en foros internacionales}

Además de las actuaciones de inspección cotidiana y formativa y de la colaboración técnica permanente en intervenciones (aduanas, jueces, Fiscalía, cuerpos de seguridad, Administraciones, etc.), hay que destacar la participación activa del SOIVRE en foros internacionales, tales como la Comisión de la UE, Europol, Interpol, representación de España en CITES, proyectos TAIEX (Technical Assistance and Information Exchange), representación de la UE en Wildlife Enforcement Networks, y grupos de trabajo de observancia en la UE, a través de los cuales se han coordinado diferentes operaciones, con participación de varios países y las correspondientes autoridades de observancia, con el objeto de combatir el tráfico ilegal de forma conjunta, poniendo en común propuestas y datos de los distintos países participantes.

La Autoridad Administrativa CITES española ha participado asiduamente en estos foros, así como en las operaciones allí organizadas que afectaban a España y al resto de miembros de la UE, y que afianzaron la colaboración internacional en la lucha contra el tráfico ilegal de especies protegidas.

\subsection{Tráfico legal vs. ilegal}

A continuación, se presentan diversos gráficos que recogen los datos del porcentaje del comercio legal e ilegal correspondientes al $D$ 

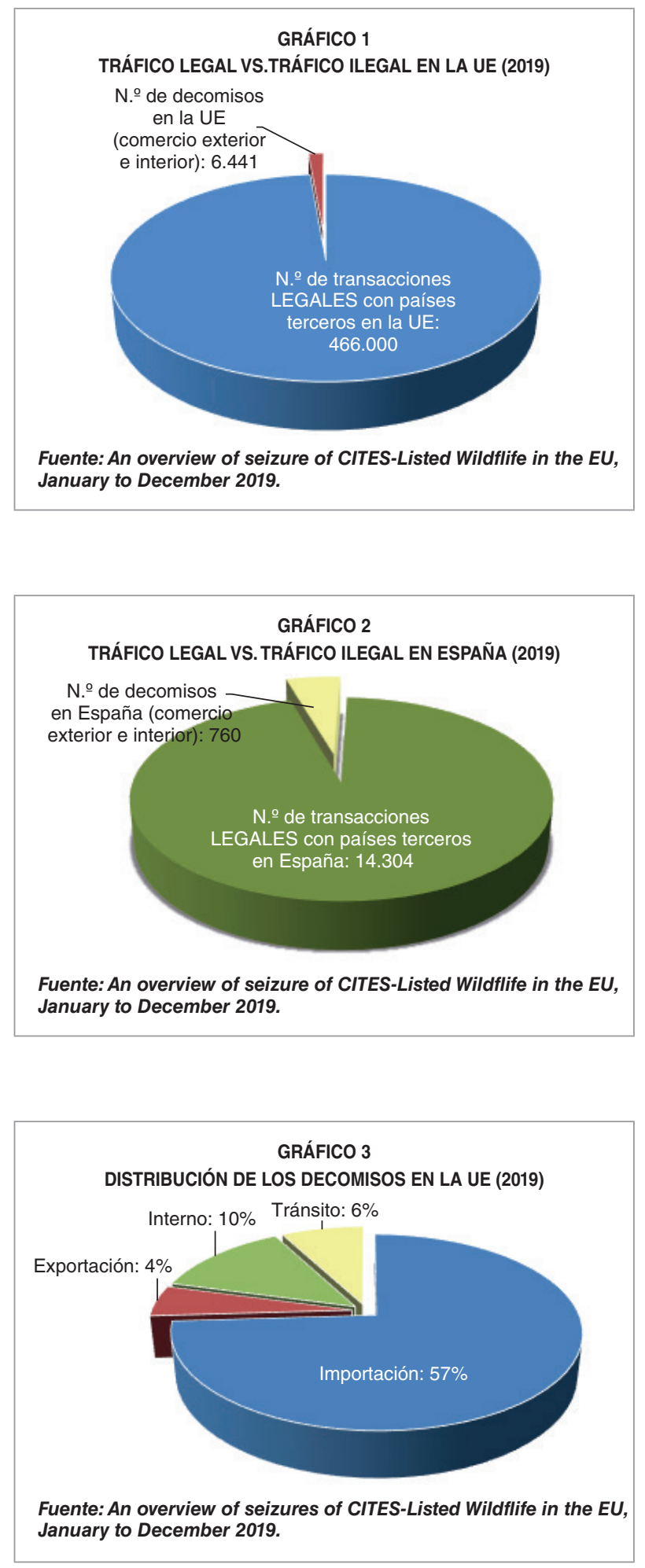

año 2019 en la UE y en España, en los que destaca la escasa relevancia del comercio ilegal, el cual se ha ido reduciendo, sin lugar a dudas, en lo últimos años. Los datos estadísticos recogidos en los gráficos se han extraído de los informes Illegal Trade Report SPAIN 2019 for EUTWIX, An overview of seizures of CITESListed Wildlife in the EU, January to December 2019 y del Informe Anual de 2019 de la Autoridad Administrativa CITES de España, a los cuales se les da difusión cada año por parte de esta autoridad administrativa, que los envía al resto de autoridades CITES en España. Asimismo, estos son publicados por la UE en su portal CITES (Environment).

En lo que respecta al comercio controlado, la autoridad administrativa tiene, entre otras obligaciones, la de elaborar para la Secretaría CITES un informe anual con los datos del comercio internacional de especímenes incluidos en los apéndices del Convenio CITES, en el que se reflejen los intercambios comerciales de España con terceros países.

En los Gráficos 1 y 2 se puede apreciar el tráfico legal vs. ilegal en la UE y en España, respectivamente. Por otra parte, en el Gráfico 3 queda reflejada la distribución de los decomisos en la UE y en el Gráfico 4, el comercio ilegal en frontera a nivel de la UE según productos.

\subsubsection{Finalidades legales de las importaciones y exportaciones CITES}

La gran mayoría de las importaciones que se llevan a cabo en España tienen una finalidad comercial; las no comerciales incluyen trofeos de caza, enseres personales, así como especímenes destinados a instituciones científicas, zoológicos, jardines botánicos, investigación biomédica, exposiciones, etc.

Con el Gráfico 5 queda ilustrado el número y el porcentaje de importaciones de especímenes CITES clasificadas según la finalidad de la importación. Asimismo, en el Gráfico 6 se puede observar, con más detalle, las principales $\triangleright$ 
Ana María Arrieta, Lucía Frechilla, Antonio Galilea, Mercedes Núñez, Mar Sanmamed y Rosa Tortajada

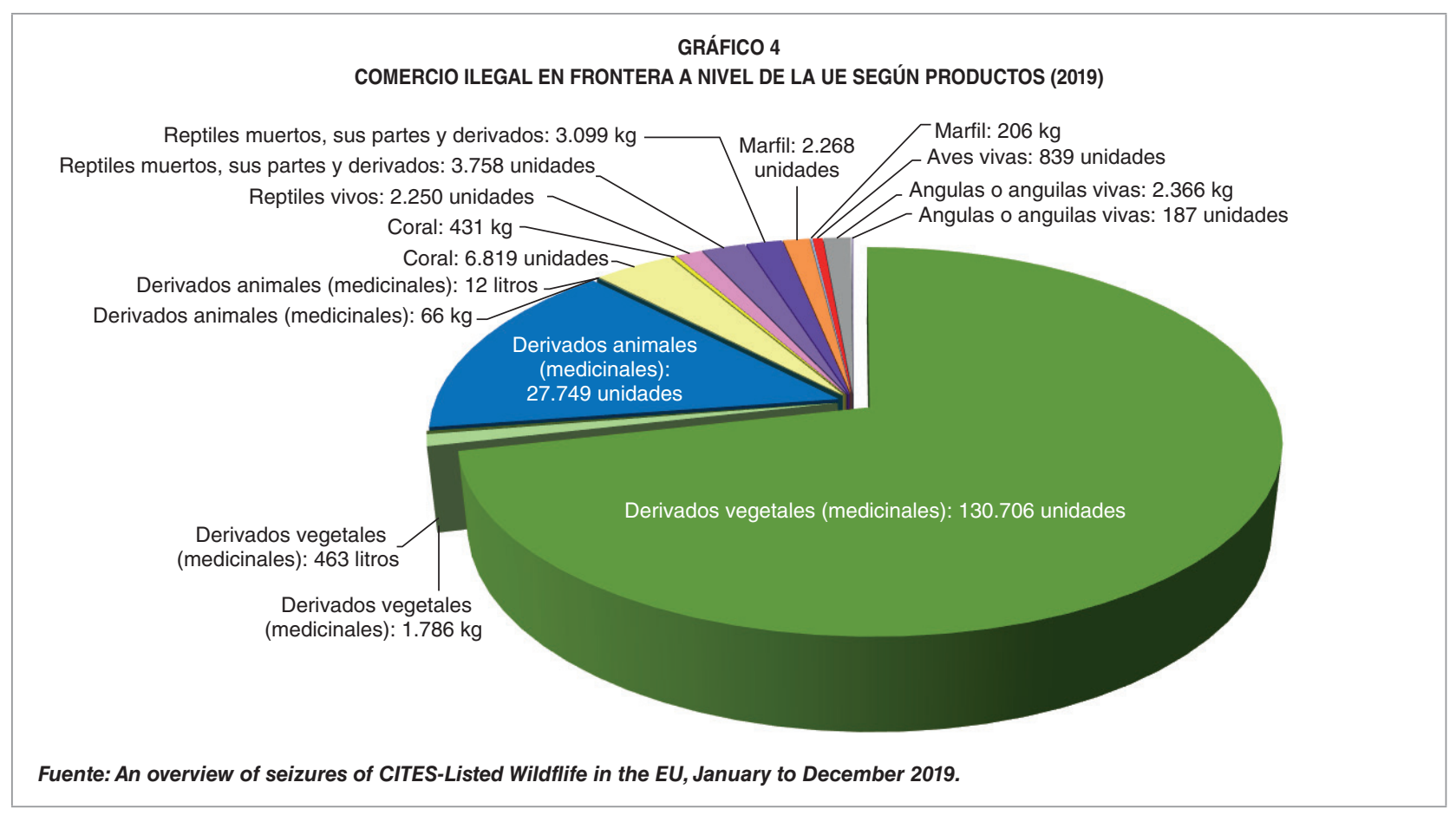

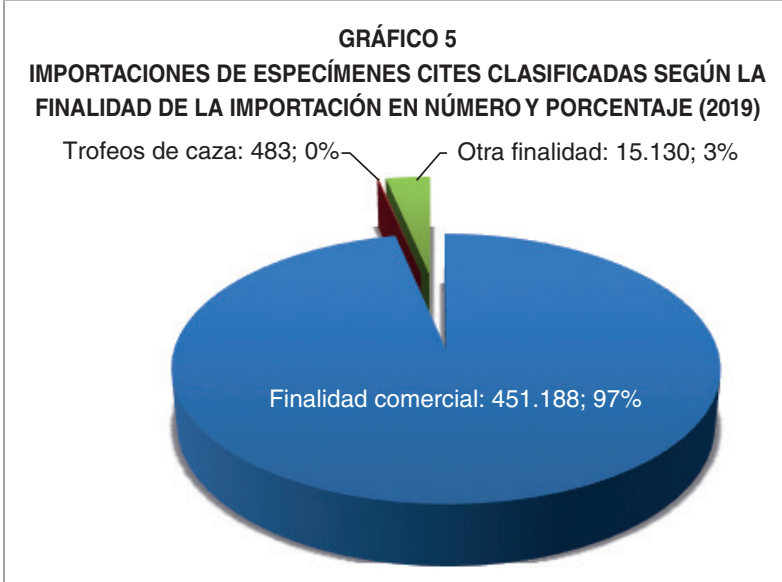

Fuente: Informe Anual 2019. Autoridad Administrativa CITES España.

partidas CITES importadas en España con finalidad comercial. El comercio de salida español es principalmente de reexportación; la exportación representa solo una pequeña fracción del total.

Las reexportaciones incluyen tanto los productos manufacturados en España a partir de materias primas (pieles, maderas, etc.) originarias de otros países como los productos que se reexportan sin haber sido transformados.
Las exportaciones afectan esencialmente a especímenes vivos originarios de España (silvestres, criados en cautividad u obtenidos mediante reproducción artificial), pero también se consideran exportaciones los especímenes originarios de otros Estados miembros de la Unión Europea. Entre las mercancías originarias de España destaca la exportación de plantas reproducidas artificialmente en viveros, así como el caviar, la carne de esturión criado en cautividad en piscifactorías y aves como halcones y psitácidas nacidas y criadas en cautividad.

En el Gráfico 7 se aprecia que casi la totalidad de las exportaciones y las reexportaciones que se autorizan tienen fines comerciales, como se ha señalado anteriormente. Tan solo es autorizada para exportar o reexportar una muy pequeña proporción de enseres personales, animales para zoológicos, especímenes para investigación biomédica, etc.

En el Gráfico 8 se presenta, de forma más detallada, las principales partidas CITES $\square$ 


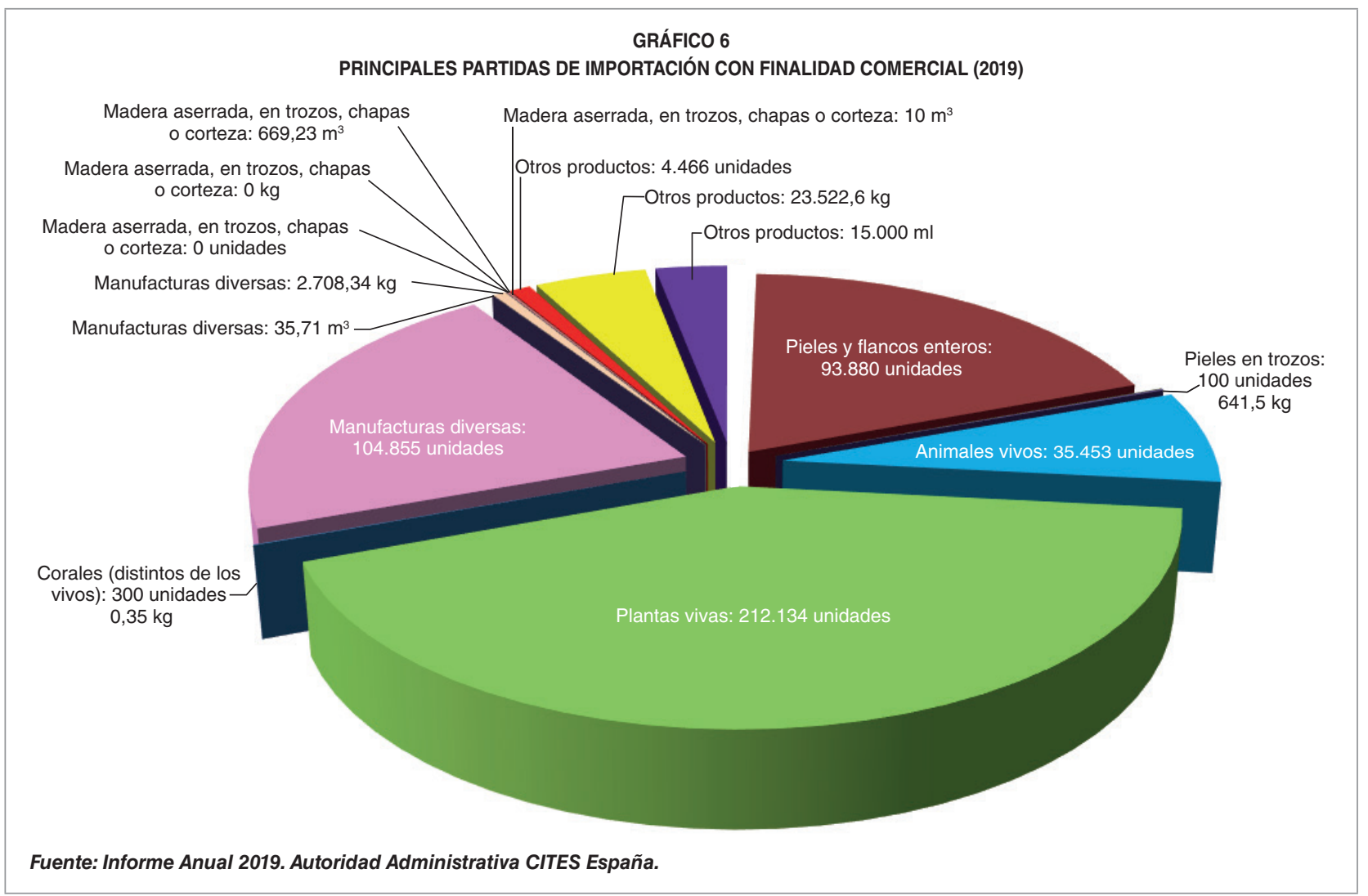

GRÁFICO 7

TOTAL DE EXPORTACIONES Y REEXPORTACIONES QUE SE AUTORIZAN CON FINES COMERCIALES (2019)

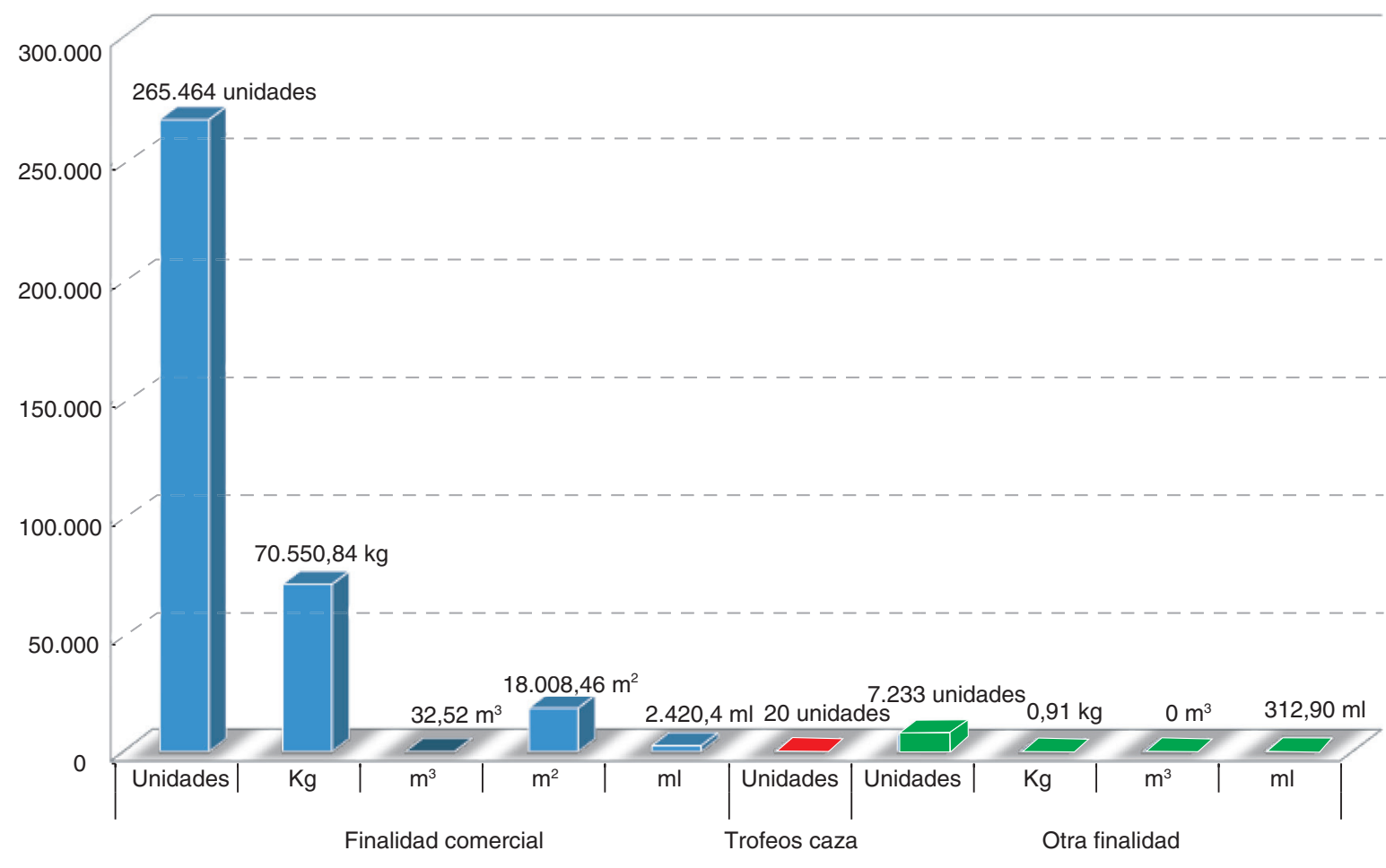

Fuente: Informe Anual 2019. Autoridad Administrativa CITES España. 
Ana María Arrieta, Lucía Frechilla, Antonio Galilea, Mercedes Núñez, Mar Sanmamed y Rosa Tortajada

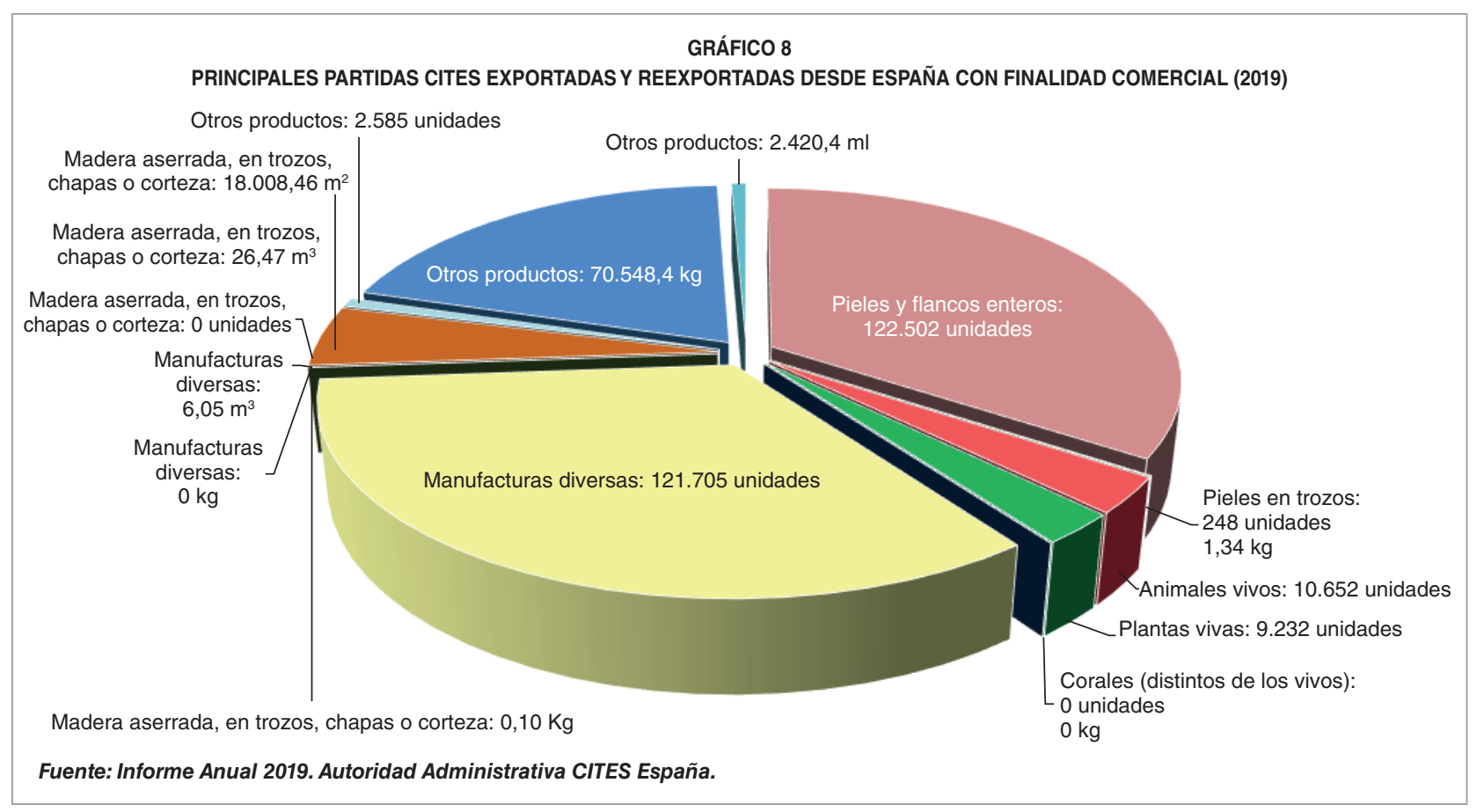

exportadas y reexportadas desde España con finalidad comercial.

El conocimiento adquirido a lo largo de tantos años de experiencia sirve de base para seleccionar los objetivos en la lucha contra el tráfico ilegal, sin interferir en el comercio legal, generador de riqueza y pilar fundamental de la Convención CITES.

\section{Conclusiones}

La puesta en marcha del Convenio CITES en España fue muy laboriosa por su complejidad, la poca disponibilidad de personal y la falta de experiencia en aquel momento. A pesar de ello, se logró poner en funcionamiento gracias al enorme esfuerzo, dedicación, profesionalidad y a la profunda convicción de los méritos del Convenio CITES como instrumento de política comercial al servicio de la conservación.

La estructura organizativa desarrollada por España para la aplicación y gestión del
Convenio CITES ha permitido adquirir gran eficacia y control, contando con personal altamente cualificado en todo el territorio nacional, lo que ha llevado a que el papel de España en la aplicación de CITES pueda calificarse de brillante.

Respecto al comercio ilegal en nuestro país, se puede concluir que ha disminuido drásticamente en todos los ámbitos de especies listadas, siendo un referente de actuación en los países comunitarios e iberoamericanos, merced a la cooperación desarrollada. El comercio ilegal de especies incluidas en CITES en la UE representa tan solo un $1 \%$ frente al comercio legal.

\section{Bibliografía}

TRAFFIC. (2019). An overview of seizures of CITESlisted Wildlife in the European Union. Comisión Europea. https://www.traffic.org/publications/reports/ an-overview-of-seizures-of-cites-listed-wildlife-inthe-eu-in-2019/

UNEP-WCMC. (2021). Base de Datos sobre el Comercio CITES. Versión 2021.1. Secretaría de la CITES. https://trade.cites.org/en/cites_trade 